\title{
Review of: "Clinical presentations and surgical outcomes of hemifacial spasm involving the vertebral artery"
}

Sang-Ku Park

Potential competing interests: The author(s) declared that no potential competing interests exist.

The vertebral artery (VA) is one of the most difficult cases for microvascular decompression (MVD) surgery in patients with hemifacial spasm (HFS).

From our experience, VA rarely acts as an offending artery alone, and most of the time, it affects the facial nerve like other arteries.

Therefore, the surgical manipulation of decompression increases, and in the process of retraction to see the blood vessels in detail, the cochlear nerve is damaged and the small blood vessels around it are damaged.

As noted in the study, it is true that the risk of neurological complications is high. There are already many such studies.

However, the study results showing a high incidence of partial spasm-free in VA-related surgeries are somewhat incomprehensible.

Could this be the reason for surgical failure due to inadequate decompression?

There have been many research reports related to this in the past as follows.

1.Masuoka, J. et al. Outcome of microvascular decompression for hemifacial spasm associated with the vertebral artery. Neurosurg.

Rev. 40, 267-273. https://doi.org/10.1007/s10143-016-0759-y (2017).

2. Kurokawa, Y., Maeda, Y., Toyooka, T. \& Inaba, K. Microvascular decompression for hemifacial spasm caused by the vertebral

artery: A simple and effective transposition method using surgical glue. Surg. Neurol. 61, 398-403.

https://doi.org/10.1016/S0090

-3019(03)00425-7 (2004).

3. Kim, J. P., Park, B. J., Choi, S. K., Rhee, B. A. \& Lim, Y. J. Microvascular decompression for hemifacial spasm associated with

vertebrobasilar artery. J. Korean Neurosurg. Soc. 44, 131-135. https://doi.org/10.3340/jkns.2008.44.3.131 (2008). 
4. Kim, J. P., Chung, J. C., Chang, W. S., Chung, S. S. \& Chang, J. W. Outcomes of surgical treatment for hemifacial spasm associated

with the vertebral artery: Severity of compression, indentation, and color change. Acta Neurochir. (Wien.) 154, 501-508. https://

doi.org/10.1007/s00701-011-1247-3 (2012).

5. Mikami, T. et al. Microvascular decompression for hemifacial spasm associated with the vertebral artery. Neurosurg. Rev. 36,

303-308. https://doi.org/10.1007/s10143-012-0425-y (2013).

6. Yang, D. B. \& Wang, Z. M. Microvascular decompression for hemifacial spasm associated with the vertebral artery. Acta Neurol.

Belg. 117, 713-717. https://doi.org/10.1007/s13760-017-0766-y (2017).

7. Otani, N. et al. Novel technical variations and increased adhesive strength in the "birdlime" transposition technique for microvascular decompression. World Neurosurg. 116, e460-e468.

https://doi.org/10.1016/j.wneu.2018.05.006 (2018)

Some studies show that obvious indentation and severe discoloration make spasm more severe, but this is not necessarily the case.

If so, there is no correlation between the obvious indentation and severe discoloration caused by VA, so that there is little spasm remaining after the operation or the recovery is slowly.

Therefore, I don't think VA-linked HFS may be a risk factor for delay and partial remissions. 